\title{
COMPARISON OF STUMP CLOSURE TECHNIQUES OF THE BASE OF THE APPENDIX IN LAPAROSCOPIC APPENDECTOMY
}

Prem Chand ${ }^{1}$, Goldendeep Singh ${ }^{2}$, Paramjit Singh Kahlon ${ }^{3}$, D. P. Singh ${ }^{4}$, Ankit Gupta $^{5}$

${ }^{1}$ Associate Professor, Department of Surgery, GMC, Patiala.

${ }^{2}$ Senior Resident, Department of Surgery, GMC, Patiala.

${ }^{3}$ Senior Resident, Department of Surgery, GMC, Patiala.

${ }^{4}$ Professor, Department of Surgery, GMC, Patiala.

${ }^{5}$ Senior Resident, Department of Surgery, GMC, Chandigarh.

\begin{abstract}
BACKGROUND

Appendicitis remains one of the most common surgical diseases. Open or laparoscopic appendectomy remains the gold standard treatment for acute appendicitis. The technique of appendectomy may vary from surgeon to surgeon or from centre to centre, starting from skin incision to ligation and invagination of appendiceal stump. However, concerns still exist regarding appendiceal stump closure.

The present study was conducted to compare the stump closure techniques of Endoloop versus Intracorporeal Transfixation of the base of the appendix in laparoscopic appendectomy to demonstrate the safety and feasibility in this surgery.
\end{abstract}

\section{MATERIALS AND METHODS}

This prospective, non-randomised, controlled study was conducted on 60 patients with appendicitis. The patients from same population were assigned to one of the two groups alternatively; A and B, each consisting of 30 patients. The patients in Group A underwent laparoscopic appendectomy with simple endoloop ligation of the base of appendix, whereas the patients in Group B underwent laparoscopic appendectomy with intracorporeal transfixation of the base of appendix. The findings of subgroups were compared and results were evaluated by IBM-Statistical Package Social Sciences (SPSS) statistical methods.

\section{RESULTS}

Position and diameter of appendix did not affect the feasibility of stump ligation with both techniques. Both techniques were comparable in terms of post-operative complications and time of appearance of bowel activity. Operative time was significantly more in intracorporeal transfixation technique.

\section{CONCLUSION}

Both the techniques are safe, sure and reliable methods for stump closure. Hence, appendix stump ligation should be left to preference of the operating surgeon.

\section{KEYWORDS}

Appendix, Appendectomy, Stump Ligation, Intracorporeal Transfixation, Endoloop Ligation.

HOW TO CITE THIS ARTICLE: Chand P, Singh G, Kahlon PS, et al. Comparison of stump closure techniques of the base of the appendix in laparoscopic appendectomy. J. Evolution Med. Dent. Sci. 2017;6(72):5092-5097, DOI: 10.14260/jemds/2017/1107

\section{BACKGROUND}

Appendicitis remains one of the most common surgical diseases. Claudius Amyand recorded the first removal of the human appendix in 1735 , during the course of an operation for hernia.[1] For more than a century, open appendectomy has been the gold standard treatment for acute appendicitis. It is considered as safe and effective procedure for acute appendicitis.[2]

The introduction of the concept of minimally invasive techniques for diagnosis and treatment of surgical conditions has castigated an era where such techniques are being applied to every possible clinical situations. Laparoscopic appendectomy was first described by Semm in 1983 in Germany. The principal purported advantages attributed to

Financial or Other, Competing Interest: None.

Submission 15-07-2017, Peer Review 24-08-2017,

Acceptance 30-08-2017, Published 07-09-2017.

Corresponding Author:

Dr. Prem Chand,

108-Hem Bagh, Kheri Gujjran Road,

Patiala-147001, Punjab.

E-mail: premchandsingl@gmail.com

DOI: $10.14260 /$ jemds $/ 2017 / 1107$

\section{(c) (i) $\odot$}

laparoscopy include- (1) Thorough visualisation of the abdominal cavity, (2) Diminution of postoperative pain and incisional complication rate, (3) Decreased hospital stay and lay-off from activity, (4) Better cosmesis. ${ }^{[2,3]}$

The technique of appendectomy may vary from surgeon to surgeon or from centre to centre, starting from skin incision to ligation and invagination of appendiceal stump. A traditional method of dealing with the appendix stump is to crush it, ligate it and then invaginate it. It has since been shown that attempts to sterilise the appendix stump do not influence the incidence of postoperative wound infection, but whether or not it is necessary to invaginate the ligated stump is still undecided.[4]

However, concerns still exist regarding appendiceal stump closure. Closure of the appendiceal stump is an important step because of postoperative complications from its inappropriate management. The development of lifethreatening events such as fistulas, postoperative peritonitis and sepsis is feared and unwanted. The tactical modification of appendiceal stump closure with a single endoligature, replacing the invaginating suture, adjusted very well to laparoscopic appendectomy and nowadays is the procedure 
of choice whenever possible. Among the alternatives that do not make use of an invaginating suture, studies advocate the use of an endostapler, endoligature (endoloop), metal clips, bipolar endocoagulation and polymeric clips.[5],[6],[7],[8],[9],,[10],[11],[12]

Thus, this prospective non-randomised study was proposed to compare the stump closure techniques using Endoloop and with intracorporeal transfixation of the base of the Appendix in laparoscopic appendectomy, to evaluate various parameters like complications, hospital stay, return of full activities.

\section{MATERIALS AND METHODS}

\section{Design and Sampling/Design}

Prospective non-randomised controlled study.

\section{Study Period}

Two years.

\section{Sampling Procedure}

Eligible male as well as female patients of appendicitis coming from Punjab and adjoining areas were selected for study for a period of two years.

\section{Justification of Sample Size}

This prospective non-randomised controlled study was conducted on 60 patients of appendicitis consisting of acute, recurrent and those kept for the interval appendectomy. This study was research clinical thesis work to be completed within two years (as per university research approval committee) and the number of patients with appendicitis reporting to our institution was about 32 to 36 patients per year at that time. So the sample size was kept to 60 patients (approved by research ethics committee) to complete the study within given time frame. All patients irrespective of age and sex were included in the study, except patients with pregnancy or coagulation disorders.

In this study for comparison of results, two groups of patients $A$ and $B$, comprising of males as well as females were made. The patients were assigned to one of the two groups alternatively: A and B, each consisting of 30 patients. Out of 60 patients, 33 were males and 27 were females. In Group A, there were 17 males and 13 females, whereas in Group B there were 16 males and 14 females. The allocation to group was done alternatively, i.e. from same population irrespective of age and sex, one patient to Group A and next patient to other Group B and so on. The patients in Group A underwent laparoscopic appendectomy with simple endoloop ligation of the base of appendix, whereas patients in Group B underwent laparoscopic appendectomy with intracorporeal transfixation of the base of appendix.

\section{Inclusion Criteria}

All patients irrespective of age and sex were included in the study.

\section{Exclusion Criteria}

Pregnant patients and patients having coagulation disorders. A detailed clinical evaluation of each case was done including proper history, physical findings, investigations, preoperative, operative and post-operative findings.

The data and additional observation if any was noted and the results were analysed statistically.

The findings of subgroups were compared and results were evaluated by using statistical methods.

\section{Statistical Analysis}

Statistical analysis was performed by IBM-Statistical Package Social Sciences (SPSS). The qualitative data were expressed as number (\%), while the continuous quantitative data as mean \pm standard deviation (SD) and data was statistically analysed by Chi-square test (was used to determine ' $p$ ' value) and Student t-test (degree of freedom and standard deviation were used to determine ' $t$ ' value). A ' $p$ ' value of $<0.05$ was considered statistically significant.

\section{Operative Technique}

All patients underwent laparoscopic appendectomy under general anaesthesia in supine position. Pneumoperitoneum created and telescope was inserted through infraumbilical port and a thorough inspection of peritoneal cavity was made for any associated pathology. The appendix was identified at the base of the caecum and any adhesions to the surrounding structures were lysed with a combination of blunt and sharp dissection supplemented with diathermy. A dissecting forceps was used to create a window in the mesoappendix. Mesoappendix was dissected away from the appendix with the help of diathermy. Ligature clips or diathermy or endoloops were used to control the appendicular artery.

In Group A, the appendix when free of its mesentery was ligated at its base with an absorbable endoloop ligature. In Group B, an intracorporeal transfixation of base of appendix was done with Vicryl 2-0. The appendix was then divided and removed in a polythene bag.

The patients were followed after 1 week, 2 weeks, 1 month post-operatively and then after 2 months. The comparison was made in terms of operating time, duration of hospital stay and return to activity and complications namely bleeding from port, secondary haemorrhage, paralytic ileus, wound infection, pyrexia/peritonitis, incisional/port site hernia, pelvic abscess and intestinal obstruction.

\section{Criteria for Discharge}

The patients were discharged only after following the set criteria-

- No new signs or symptoms after the operation.

- No active bleeding or oozing.

- Orientation to person, time and place.

- Pain controllable with oral analgesics.

- Passed urine.

- No surgical complication.

\section{Instructions on Discharge}

Written and verbal instructions regarding post-operative medication, oral intake and complications were given.

\section{RESULTS}

Most of the patients were in the age group of 11 - 30 years. The youngest case in our study was 9 years, whereas the 
oldest patient was 63 years old. Patients $<10$ years old comprised only $5 \%$ and patients $>50$ years old were only $3 \%$ of the total. This reflects low incidence of appendicitis in extremes of age. Appendicitis was more common in male gender (55\%). The most common presenting complaint was pain in abdomen followed by nausea and vomiting. All the patients had pain abdomen and $67 \%$ had nausea and vomiting.

The most common position of appendix noticed was retrocaecal followed by pelvic. Three women patients had additional findings. Out of these, 2 (3.3\%) had polycystic ovaries and $1(1.7 \%)$ had unilateral right ovarian cyst.

The operative time was significantly ( $\mathrm{p}$ value 0.00 and $\mathrm{t}$ value 5.49) longer in intracorporeal transfixation.

(Group B)- The average time was $49.33 \pm 8.78$ minutes for intracorporeal transfixation.

(Group B) and $36.83 \pm 8.85$ minutes for the endoloop (Group A) [Table-1].

Wide base (diameter $>10 \mathrm{~mm}$ ) was seen in three cases $(10 \%)$ in Group A and four cases (13.3\%) in Group B. The diameter of base of appendix did not affect the feasibility of stump ligation.

The bowel sounds returned after $20.40 \pm 8.99$ hours in patients of Group A and after $18.80 \pm 8.14$ hours in patients of Group B, but this difference was statistically insignificant $(\mathrm{P}$ value 0.473 and $t$ value 0.722 ) [Table-2]. Two patients in Group A and one patient in Group B had wound infection. One patient in Group A had post-operative pyrexia as compared to three patients in Group B. None of the patients had port site hernia in 3 months followup period. No bleeding from the port was encountered in both the groups. No patient developed intestinal obstruction in the given period of followup. No patient had postoperative peritonitis. Thus, both groups had similar rate of complications [Table-3].

$21(35 \%)$ patients were discharged on the same day. One patient in the Group B was discharged on the $3^{\text {rd }}$ post-op day due to post-operative pyrexia. The cause of pyrexia was found to be the infection of the port site. Most (75\%) of the patients were discharged either on the same day or the next day. The mean stay in endoloop group was $0.933 \pm 0.739$ days as compared to $0.833 \pm 0.833$ days in transfixation group. But the difference was statistically insignificant $(\mathrm{p}=$ 0.625 and t value 0.491 ) [Table-4].

\begin{tabular}{|c|c|c|c|c|}
\hline \multirow{2}{*}{$\begin{array}{c}\text { Operative } \\
\text { Time (min) }\end{array}$} & Group A Endoloop & \multicolumn{2}{c|}{ Group B ICT } \\
\cline { 2 - 5 } & N= 30 & Percent & N= 30 & Percent \\
\hline $21-30$ & 11 & 36.67 & 01 & 03.33 \\
\hline $31-40$ & 12 & 40.00 & 06 & 06.67 \\
\hline $41-50$ & 05 & 16.67 & 15 & 50.00 \\
\hline $51-60$ & 02 & 06.67 & 04 & 13.33 \\
\hline$>60$ & 00 & 00 & 03 & 10.00 \\
\hline Mean \pm SD & \multicolumn{5}{|c|}{$36.83 \pm 8.85$} & $49.33 \pm 8.78$ \\
\hline P value & \multicolumn{5}{|c|}{0.00} \\
\hline Significance & HS \\
\hline t value & \multicolumn{5}{|c|}{ Table 1. Operative Time } \\
\hline \multicolumn{5}{|c|}{ Group A } \\
\hline Return of Bowel & Group B \\
\hline
\end{tabular}

\begin{tabular}{|c|c|c|c|c|}
\hline \multirow{2}{*}{ Habits (hrs.) } & \multicolumn{2}{|c|}{ Endoloop } & \multicolumn{2}{c|}{ ICT } \\
\cline { 2 - 5 } & $\mathbf{N = 3 0}$ & $\mathbf{\%}$ & $\mathbf{N}=\mathbf{3 0}$ & $\mathbf{\%}$ \\
\hline $11-20$ & 14 & 46.67 & 16 & 53.33 \\
\hline $21-30$ & 11 & 36.67 & 11 & 36.67 \\
\hline $31-40$ & 05 & 16.67 & 03 & 10.00 \\
\hline Mean \pm SD & $20.40 \pm 8.99$ & $18.80 \pm 8.14$ \\
\hline P value & \multicolumn{3}{|c|}{0.473} \\
\hline Significance & \multicolumn{3}{|c|}{ NS } \\
\hline t value & \multicolumn{3}{|c|}{0.722} \\
\hline Table 2. Return of Bowel Sounds \\
\hline
\end{tabular}

\begin{tabular}{|c|c|c|}
\hline \multirow{2}{*}{$\begin{array}{c}\text { Post-Operative } \\
\text { Complication }\end{array}$} & $\begin{array}{c}\text { Group A } \\
\text { Endoloop }\end{array}$ & $\begin{array}{c}\text { Group B } \\
\text { ICT }\end{array}$ \\
\cline { 2 - 3 } & $\mathbf{N = 3 0}$ & N= 30 \\
\hline Pyrexia & 01 & 03 \\
\hline Wound infection & 02 & 01 \\
\hline Port site hernia & 0 & 0 \\
\hline Bleeding from the port & 0 & 0 \\
\hline Peritonitis & 0 & 0 \\
\hline Intestinal obstruction & 0 & 0 \\
\hline P value & \multicolumn{2}{|c|}{0.27} \\
\hline Significance & \multicolumn{2}{|c|}{} \\
\hline \multicolumn{2}{|c|}{ Table 3. Postoperative Complications } \\
\hline
\end{tabular}

\begin{tabular}{|c|c|c|c|c|}
\hline \multirow{2}{*}{ Stay in the Hospital } & \multicolumn{2}{|c|}{$\begin{array}{c}\text { Group A } \\
\text { Endoloop }\end{array}$} & \multicolumn{2}{c|}{$\begin{array}{c}\text { Group B } \\
\text { ICT }\end{array}$} \\
\cline { 2 - 5 } & N= 30 & \% & N= 30 & $\%$ \\
\hline 0 & 09 & 30.00 & 12 & 40.00 \\
\hline 1 & 14 & 46.67 & 12 & 40.00 \\
\hline 2 & 07 & 23.33 & 05 & 06.67 \\
\hline 3 & 00 & 00 & 01 & 03.33 \\
\hline Mean \pm SD & $0.933 \pm 0.739$ & $0.833 \pm 0.833$ \\
\hline P value & \multicolumn{5}{|c|}{0.625} \\
\hline Significance & \multicolumn{5}{|c|}{0.491} \\
\hline t value & \multicolumn{5}{|c|}{} \\
\hline Table 4. Stay in the Hospital \\
\hline
\end{tabular}

\begin{tabular}{|c|c|c|c|}
\hline Study & Year & $\begin{array}{c}\text { Time taken for } \\
\text { Endoloop } \\
\text { (min) }\end{array}$ & $\begin{array}{c}\text { Time taken for } \\
\text { Intracorporeal } \\
\text { Transfixation } \\
\text { (min) }\end{array}$ \\
\hline $\begin{array}{c}\text { M. Kieudelis } \\
\text { et al }\end{array}$ & 2013 & $58.4 \pm 14.3$ & $79.6 \pm 21$ \\
\hline Ates M & 2012 & - & $62.81 \pm 15.4$ \\
\hline Gonenc M & 2012 & - & 61.9 \\
\hline Hady S & 2014 & - & 45 \\
\hline $\begin{array}{c}\text { Naiditch J } \\
\text { et al }\end{array}$ & 2010 & $52.2 \pm 15.8$ & - \\
\hline $\begin{array}{c}\text { Akybiyik F } \\
\text { et al }\end{array}$ & 2011 & 39.7 & - \\
\hline $\begin{array}{c}\text { Delibegović S } \\
\text { et al }\end{array}$ & 2008 & $47.1 \pm 6.7$ & - \\
\hline Present Study & & $36.83 \pm 8.85$ & $49.33 \pm 8.78$ \\
\hline \multicolumn{4}{|c|}{ Table 5. Operative Time } \\
\hline
\end{tabular}




\begin{tabular}{|c|c|c|c|c|c|c|c|c|c|c|c|c|}
\hline \multirow[t]{2}{*}{ Study } & \multirow[t]{2}{*}{ Year } & \multicolumn{2}{|c|}{$\begin{array}{c}\text { No. of } \\
\text { Patients }\end{array}$} & \multicolumn{2}{|c|}{$\begin{array}{c}\text { Complications } \\
(\%)\end{array}$} & \multirow[t]{2}{*}{$\mathbf{P}$} & \multicolumn{2}{|c|}{$\begin{array}{c}\text { Wound } \\
\text { Infections (\%) }\end{array}$} & \multirow[t]{2}{*}{$\mathbf{P}$} & \multicolumn{2}{|c|}{$\begin{array}{l}\text { Intra-abd, Surgical } \\
\text { Site Infection (\%) }\end{array}$} & \multirow[t]{2}{*}{$\mathbf{P}$} \\
\hline & & Endo & ICT & Endo & ICT & & Endo & ICT & & Endo & ICT & \\
\hline $\begin{array}{l}\text { M. Kieudelis } \\
\text { et al }\end{array}$ & 2013 & 112 & 40 & 9.8 & 7.5 & $>0.05$ & 2.7 & o & NS & 3.6 & 5 & NS \\
\hline Gonenc M & 2012 & & 46 & & $8.7 \%$ & & & & & & & \\
\hline Hady S & 2014 & & 100 & & $3 \%$ & & & & & & & \\
\hline B. Mayir & 2014 & 61 & & 3 & & & 1.6 & & & 3.2 & & \\
\hline G. Beldi & 2004 & 99 & & 5.1 & & & 1 & & & 4 & & \\
\hline Naiditch J & 2010 & 309 & & 5.5 & & & 5.5 & & & & & \\
\hline Janczak D & 2011 & 33 & & 3 & & & 3 & & & & & \\
\hline Present Study & & 30 & 30 & 10 & 13.3 & 0.27 & 6.7 & 3.3 & Ns & - & - & \\
\hline & & & & $T a b$ & (Perc & gge of & mpli & ons) & & & & \\
\hline
\end{tabular}

\section{DISCUSSION}

Acute appendicitis is one of the most common cause of acute abdomen. For more than a century, open appendectomy has been the gold standard for acute appendicitis. It is considered safe and effective procedure for acute appendicitis. Variability in the inflammatory process and in the location of appendix are the main causes of operative difficulties in open appendectomy, besides providing only a limited space for abdominal exploration. [2] Laparoscopic appendectomy holds a number of theoretical advantages over the traditional open operation. These include decreased incidence of wound infection, less pain for the patient, reduced hospitalisation and a more rapid return to employment[13] and better cosmesis.[2] Because of faster postoperative recovery and reduced postoperative complications, laparoscopic appendectomy is now being more and more widely used for treating acute appendicitis.[14],[15],[16],[17],[18]

The key technical aspect in laparoscopic appendectomy is the treatment of appendix stump closure. Nowadays, stapling and endoloop techniques are the most popular ones in securing the appendix stump. Some randomised and prospective clinical trials[10],[11],[12] have compared staplers and endoloop for appendix stump closure, but did not find any significant difference in the incidence of intra-abdominal abscess. The authors noted that appendix stump closure using an endoloop is an easy, safe and cost-effective procedure. Securing the appendix stump with endoloop involves the application of one or two proximal ligatures and one distal ligature around the base of the appendix, which results in extraversion of the appendix stump mucosa as opposed to the inversion of the mucosa with stapling devices. ${ }^{[8]}$ Closure of the stump of the appendix with a stapler is a simple but more expensive method when compared with others.[19],[20],[21],[22] Closure with endoloop is a common way and has a lower cost than a stapler.[19]

Our study compared 30 cases each of endoloop and intracorporeal transfixation method for ligation of base of appendix in laparoscopic appendectomy to evaluate outcome of various parameters.

\section{Age}

The mean age in our study group was 29.01 years, which is similar to the mean age in other studies. The cause of high incidence of appendicitis in the second and third decade of life is considerably due to hyperplasia of lymphoid tissue in the appendix, which reaches its peak at 20 years of age and thereafter atrophy of the lymphoid tissue begins.[23]

\section{Sex}

The male-to-female ratio in our study was $1.22: 1 ; 55 \%$ of the patients were males, which is quite similar to other studies.

\section{The Clinical Presentation at the Time of Admission}

The most common presenting complaint was pain abdomen followed by nausea and vomiting.

\section{Intraoperative Location of Appendix}

Retrocaecal position was the most common position in our study, which is consistent with results of studies by Ortega et al and Rohr et al. Wakeley and Child (1950)[24] found retrocaecal position of appendix in $59.1 \%$ cases and in our study it was $60 \%$. The position of appendix did not affect the efficacy and feasibility of endoloop or intracorporeal transfixation.

\section{Operative Time}

The Operative time was longer in intracorporeal transfixation group as compared to the time taken in the Endoloop group. The difference is statistically significant ( $p$ value 0.00 and $t-$ value 5.49) [Table-1]. Operative time in Kiudelis et al (2013) ${ }^{[25]}$ study was significantly longer because invaginating suture was also used in the study, otherwise results of our study are comparable with most of the studies as shown in table [Table-5].

\section{Return of Bowel Sounds}

The bowel sounds returned after $20.40 \pm 8.99$ hours in patients of endoloop (Group A) and after $18.80 \pm 8.14$ hours in patients of the intracorporeal transfixation (Group B). But this difference is statistically insignificant $(\mathrm{P}=0.473, \mathrm{t}=0.722)$ [Table-2], which is in accordance with other studies.

\section{Complications}

In a study done by M. Kiudelis et al (2013),[25] there were no significant differences between the two groups in the overall intraoperative and postoperative complication rate. M. Kiudelis et al reported superficial surgical site infection in $2.7 \%$ cases of endoloop group and none in case of intracorporeal transfixation (ICT) group. B. Mayir et al $(2014)^{[26]}$ reported surgical wound infection in $1.6 \%$ of patients undergoing surgery using endoloop. Naiditch J et al (2010) ${ }^{[27]}$ reported superficial wound infection in the nonperforated endoloop group (17/309, 5.5\%). Janczak D $(2011)^{[28]}$ reported wound infection in 1 patient out of 33 (3\%) cases undergoing surgery using endoloop. In our study, two patients in the endoloop group and one patient in 
intracorporeal transfixation group had wound infection [Table-3 and 6].

M. Kiudelis et al (2013)[25] reported intra-abdominal surgical site infection in 3.6\% cases of endoloop group and $5 \%$ cases of ICT group. No such complication was seen in our study in any group.

One patient in Group A had post-operative pyrexia as compared to three patients in Group B. The cause was found to be wound infection in one case. All the patients were managed conservatively.

Among intraoperative complications, M. Kiudelis et al (2013) ${ }^{[25]}$ reported bleeding in $2.5 \%$ of cases of ICT group and in $1.8 \%$ of cases of endoloop group. No such complication was encountered in both the groups in our study.

Hady S et al (2014) ${ }^{[29]}$ compared ICT with metallic clips. He reported post-op complications in $3 \%$ of patients undergoing ICT; 2 patients had wound infections and one patient had delayed return of bowel sounds after 72 hours and improved by medication. None of the patient in our study had delay in return of bowel sounds.

It was noticed in this study that the condition of the base of the appendix and not the distal part of the appendix, affected the applicability of both techniques. Severe friability or necrosis of the base of appendix made the application of both techniques impossible and risky.

There was no conversion to open surgery as in our study. After $8 \mathrm{hrs}$. of operation, all patients allowed oral intake. During the post-operative period, one surgical wound infection (1.6\%) and two intra-abdominal abscesses (3.2\%) were detected. When those two patients were operated on again, abscess in the Douglas of Pouch was detected, while the stump of the appendix and caecum were normal. There was no leakage from the stump of the appendix in any patient.

None of the patients had port site hernia in 3 months followup period.

No case of intra-peritoneal adhesion requiring surgery was reported in present study in 3 months followup period. A longer period of followup might be required to draw any conclusions. Post-operative peritonitis was not seen in any of our cases. There were no deaths in the post-operative period.

\section{Wide Base}

The diameter of base of appendix $>10 \mathrm{~mm}$ is considered as wide base. In our study, wide base was seen in 3 cases $(10 \%)$ of endoloop group and 4 cases $(13.3 \%)$ of intracorporeal transfixation group.

Hady S et al (2014) ${ }^{[29]}$ stated that one more reason for failure is an appendix with a wide base of more than $10 \mathrm{~mm}$ during MCC as clips do not close all diameters of the appendix. The use of mechanical stapler can circumvent the problem; however, it was not used in our study and management was performed successfully by ICT and base invagination by purse-string sutures. In both techniques, failure of securing the stump was managed by gentle ligation at the most firm viable point close to the cecum, and then reinforced by purse-string sutures and base invagination. He concluded that both ICT and metallic clip closure techniques were safe and economic in securing the appendix stump except for wide, severely oedematous or gangrenous base, wherein the metallic clip closure technique was not appropriate and was inferior to knotting. In our study, wide base of appendix was managed without failure and without any intra-operative or post-operative complications (Intraabdominal sepsis or stump blowout) in both the groups. Though the intracorporeal transfixation technique has theoretical advantage over endoloop in managing wide base of appendix, but we found both the techniques equally feasible.

\section{Post-Operative Hospital Stay}

Post-operative hospital stay was similar in both the groups. No significant statistical difference was found. M. Kieudelis et al (2013) ${ }^{[25]}$ also reported no significant difference in postoperative hospital stay between the two groups [Table-4].

Completion of followup was $100 \%$ in our study. Limitation of the study is low sample size.

\section{CONCLUSION}

The most common position of appendix was retrocaecal and position of appendix did not affect the feasibility of stump ligation. Although operative time was significantly more in intracorporeal transfixation technique, but with more experience in intracorporeal transfixation technique difference of operative time of both the techniques may become insignificant. The diameter of base of appendix did not affect the feasibility of stump ligation. Both the groups were comparable in terms of post-operative complications. There were no major complications like peritonitis or faecal fistula. Post-operative stay was similar in both the groups.

It was concluded that both the techniques are safe, sure and reliable method for stump closure. Thus, the method of dealing with appendix stump can be left to the personal preference of the operating surgeon.

\section{REFERENCES}

[1] Amyand C. An inguinal rupture, with a pin in the appendix caeci encrusted with stone: some observations on wounds in the gut. Phiosoph Trans $\mathrm{R}$ Soc Land 1736;39:329-42.

[2] Fingerhut A, Millat B, Borrie F. Laparoscopic versus open appendectomy: time to decide. World J Surg 1999;23(8):835-45.

[3] Yong JL, Law WL, Lo CY, et al. A comparative study of routine laparoscopic versus open appendectomy. JSLS 2006;10(2):188-92.

[4] Watters DA, Walker MA, Abernethy BC. The appendix stump: should it be invaginated? Ann R Coll Surg Engl 1984;66(2):92-3.

[5] Gonenc M, Gemici E, Kalayci MU, et al. Intracorporeal knotting versus metal endoclip application for the closure of the appendiceal stump during laparoscopic appendectomy in uncomplicated appendicitis. J Laparoendosc Adv Surg Tech A 2012;22(3):231-5.

[6] Alis H, Gonenc M, Deniztas C, et al. Metal endoclips for the closure of the appendiceal stump in laparoscopic appendectomy. Tech Coloproctol 2012;16(2):139-41.

[7] Beldi G, Vorburger SA, Bruegger LE, et al. Analysis of stapling versus endoloops in appendiceal stump closure. Br J Surg 2006;93(11):1390-3.

[8] Beldi G, Muggli K, Helbling C, et al. Laparoscopic appendectomy using endoloops: a prospective, randomized clinical trial. Surg Endosc 2004;18(5):749-50. 
[9] Kazemier G, In't Hof KH, Saad S, et al. Securing the appendiceal stump in laparoscopic appendectomy: evidence for routine stapling? Surg Endosc 2006;20(9):1473-6.

[10] Klima S. Importance of appendix stump management in laparoscopic appendectomy. Zentralbl Chir 1998;123 (Suppl 4):90-3.

[11] Hanssen A, Plotnikov S, Dubois R. Laparoscopic appendectomy using a polymeric clip to close the appendicular stump. JSLS 2007;11(1):59-62.

[12] Sahm M, Kube R, Schmidt S, et al. Current analysis of endoloops in appendiceal stump closure. Surg Endosc 2011;25(1):124-9.

[13] Rosemary A, Kozar, Roslyn JJ. The appendix. In: Schwartz SI, Shires GT, Spencer FC, et al. Principles of surgery. $7^{\text {th }}$ edn. New York: McGraw-Hill 1999;2:138392.

[14] Bennett J, Boddy A, Rhodes M. Choice of approach for appendicectomy: a meta-analysis of open versus laparoscopic appendicectomy. Surg Laparosc Endosc Percutan Tech 2007;17(4):245-55.

[15] Liu Z, Zhang P, Ma Y, et al. Laparoscopy or not: a metaanalysis of the surgical effects of laparoscopic versus open appendicectomy. Surg Laparosc Endosc Percutan Tech 2010;20(6):362-70.

[16] Guller U, Hervey S, Purves H, et al. Laparoscopic versus open appendectomy: outcomes comparison based on a large administrative database. Ann Surg 2004;239(1): 43-52.

[17] Duda M, Ryga A, Zudek S, et al. Twenty years of minimally invasive surgery in the Czech Republic. Videosurgery Miniinv 2011;6:42-7.

[18] Rembiasz K, Bobrzyński A, Budzyński A, et al. Analysis of complications of laparoscopic management of abdominal diseases related to extended indications. Wideochir Inne Tech Malo Inwazyjne2010;5(2):53-9.

[19] Kehagias I, Karamanakos SN, Panagiotopoulos S, et al. Laparoscopic versus open appendectomy: which way to go? World J Gastroenterol 2008;14(31):4909-14.
[20] Yildiz F, Terzi A, Coban S, et al. The handmade endoloop technique. A simple and cheap technique for laparoscopic appendectomy. Saudi Med J 2009;30(2): 224-7.

[21] Partecke LI, Kessler W, von Bernstorff W, et al. Laparoscopic appendectomy using a single polymeric clip to close the appendicular stump. Langenbecks Arch Surg 2010;395(8):1077-82.

[22] Arcovedo R, Barrera H, Reyes HS. Securing the appendiceal stump with the Gea extracorporeal sliding knot during laparoscopic appendectomy is safe and economical. Surg Endoscop 2007;21(10):1764-7.

[23] Ronan P, O'Connell. The vermiform appendix. In: Bailey and Love's short practice of surgery. 24th edn. London: Arnold Publishers 2004:1203-18.

[24] Wakeley C, Childs P. Appendicitis. British Medical Journal 1950;2(4693):1347, 1348-1, 1349-52.

[25] Kiudelis M, Ignatavicius P, Zviniene K, et al. Analysis of intracorporeal knotting with invaginating suture versus endoloops in appendiceal stump closure. Wideochir Inne Tech Maloinwazyjne 2013;8(1):69-73.

[26] Mayir B, Bilecik T, Ensari CO, et al. Laparoscopic appendectomy with hand-made loop. Wideochir Inne Tech MaloInwazyjne 2014;9(2):152-6.

[27] Naiditch J, Lautz T, Chin A, et al. Endoloop as the first line tool for appendiceal stump closure in children with appendicitis. Eur J Pediatr Surg 2013;25(2):1559.

[28] Janczak D, Merenda M, Litarski A, et al. Use of polymeric clips in laparoscopic appendectomy. Polim Med 2011;41(3):19-23.

[29] Ashour HSA. Evaluation of intracorporeal knotting and metallic clipping of the appendicular stump in laparoscopic appendicectomy. The Egyptian Journal of Surgery 2014;33(3):188-93. 